\title{
Current Perspective of Zika Virus and Vaccine Development
}

\author{
Smarajit Manna ${ }^{1,2}$, Sumanta Dey², Subhamoy Biswas ${ }^{3}$, Ashesh Nandy $^{2 *}$ (i) \\ and Subhash Chandra Basak ${ }^{4}$ \\ ${ }^{1}$ Jagadis Bose National Science Talent Search, Kolkata, India; ${ }^{2}$ Center for Interdisciplinary Research and Education, \\ Kolkata, India; ${ }^{3}$ Jadavpur University, Department of Electrical Engineering, Kolkata, India; ${ }^{4}$ University of Minnesota, \\ Department of Chemistry and Biochemistry, Duluth, Minnesota, USA
}

\begin{abstract}
In our previous review published in 2017 on the Zika virus pandemic sweeping the Western World, we mentioned that understanding viral pandemics and vaccine preparedness is vital to combating new outbreaks. In this review, we discuss key updated aspects of the Zika virus in terms of its origin, present status, and prognosis. We also discuss developments in the preventive measure of designing a vaccine to limit the fatal effects of the virus in its current or mutated form. By summarizing updated knowledge of the Zika virus and its effects, we aim to understand how modern technology may help in this objective and how we can apply our knowledge to help mitigate the crises caused by other deadly viruses, such as severe acute respiratory syndrome coronavirus 2 (SARS-CoV-2).
\end{abstract}

Introduction

The Zika virus epidemic in Brazil in 2015 and the subsequent development into pandemic form caught the scientific community by surprise. Even though the intensity of the Zika virus is much lower now compared to what it was before, the virus is still being transmitted in Southeast and South Asia, as well as other various parts of the globe. For example, in the year 2020 (up to $5^{\text {th }}$ September 2020), confirmed Zika virus cases spanned across various countries in the Americas, including Brazil (1,313 cases), Puerto Rico (22 cases), Bolivia (12 cases), Mexico (6 cases), and Colombia (1 case). ${ }^{1}$ Like other RNA viruses, Zika virus exhibits a large probability for mutation and may develop into new outbreaks that need intense study and surveillance. In this review, we consider new knowledge of Zika virus and describe the status of preventive measures, therapeutics, and technological approaches that have been developed to combat such eventualities with the Zika virus

Keywords: Zika virus; Viral pandemic; Preventative measures; COVID-19; Zika virus; SARS-CoV-2; Vaccine.

Abbreviations: ADE, Antibody-dependent enhancement; CDC, Centre for Disease Control; COVID-19, coronavirus disease 2019; DNA, deoxy-ribonucleic acid; HIV, human immunodeficiency viruses; NIAID, National Institute of Allergy and Infectious Diseases; NS1, non-structural protein 1; SARS-CoV-2, severe acute respiratory syndrome coronavirus 2; WHO, World Health Organization; WRAIR, Walter Reed Army Institute of Research.

Received: September 29, 2020; Revised: November 25, 2020; Accepted: November 26, 2020

${ }^{*}$ Correspondence to: Ashesh Nandy, Centre for Interdisciplinary Research and Education, Kolkata, India. ORCID: http://orcid.org/0000-0002-1649-7731. Tel: +9194335-79452,E-mail: anady43@yahoo.com

How to cite this article: Manna S, Dey S, Biswas S, Nandy A, Basak SC. Curren Perspective of Zika Virus and Vaccine Development. Exploratory Research and Hypothesis in Medicine 2020;000(000):000-000. doi: 10.14218/ERHM.2020.00060. and perhaps other epidemics to come.

Origin and epidemiology

Zika virus was named after the Zika forest, located in Uganda, from where it was first identified and isolated in the year 1947 from a rhesus monkey. ${ }^{2} 1952$ marked the first reported case of Zika virus infection in humans in Uganda and Tanganyika, and antibodies thereof were soon after found in human blood or in mosquitoes in several countries. ${ }^{3,4}$ The emergence of the virus as an outbreak in 2007 in the Yap Island of Federated States of Micronesia marked the beginning of the new outbreaks. This initial event was soon followed in 2013-2014 by another outbreak of the virus in French Polynesia and other Pacific Islands. ${ }^{5,6}$ Most recently, the outbreak that caught the scientific community by surprise was the Brazilian epidemic of 2015 which led to a high incidence of birth defects as a result of viral infection. ${ }^{7}$

Initially, this epidemic was believed to include the first reported cases in America, but Grubaugh et al. ${ }^{8}$ later showed by genomic sequence studies that Zika viral infection started in the north-eastern part of the country in 2013. The rapid catastrophic spread of the virus in other parts of America led the PAN American Health Organization and World Health Organization (WHO) to issue an epidemiological alert and to declare the outbreak a Public Health Emergency of International Concern in February 2016. After reaching such a peak, Zika virus infections declined during 2017 2018 (Table 1). ${ }^{1}$ In 2017, three cases were reported in Ahmedabad, India, and several locally transmitted Zika cases were confirmed in Singapore. ${ }^{4}$ Subsequently, 195 cases were reported in India and several cases in Indonesia, Thailand, and Laos, where about $9 \%$ of the Lao children were found to have had prior exposure to the virus. Cases of microcephaly and foetal death have been reported as 
Table 1. From the report of PAHO/WHO, ${ }^{1}$ total number of Zika infection cases (suspected and confirmed) in the Americas during the last five years

\begin{tabular}{lll}
\hline Year & Total cases & Confirmed cases \\
\hline 2015 & 78,858 & 19,807 \\
2016 & 651,590 & 199,614 \\
2017 & 57,543 & 19,790 \\
2018 & 31,576 & 3,589 \\
2019 & 33,896 & 6,640 \\
2020 (till 05/09/2020) & 11,909 & 1,354 \\
\hline
\end{tabular}

a result of viral infection in several Asian countries such as Thailand, Vietnam, and others. ${ }^{9-11}$ Nevertheless, in a twist of fate, the American strain of Zika virus was found to have spread to Angola in 2017-18 and caused instances of microcephaly. ${ }^{12}$

According to the 2019 Zika Epidemiology Update from the $\mathrm{WHO},{ }^{12}$ autochthonous mosquito-borne transmission of the virus spanned over 87 countries and territories across the African region, the region of the Americas, South-East Asia region, and the western pacific region (see Fig. 1 for an update geographical distribution of Zika virus spread). The Centre for Disease Control (CDC) of the USA in its report dated $3^{\text {rd }}$ September 2020 provisionally noted one new case of Zika virus in the state of Virginia and 13 cases in Puerto Rico. ${ }^{13}$ These recent cases indicated that Zika infection continues, albeit on a much-reduced scale compared to previous outbreaks.

\section{Molecular aspects and structure of Zika virus}

Zika virus is a member of the Flavivirus genus and Flaviviridae family that also includes viruses such as Dengue, West Nile Virus, Japanese Encephalitis, Spondweni, Yellow Fever Virus, etc. ${ }^{14}$ Similar to other viruses, Zika virus consists of an envelope, i.e., a capsid, and an inner core of nucleic acid. The virion is spherical in shape with a diameter of approximately $50 \mathrm{~nm}$ and includes an electron-dense core with an approximate diameter of $30 \mathrm{~nm}$. The whole genome of Zika virus is approximately 10,700 base pairs long and is comprised of a single-stranded, positive-sense RNA. The genome is encapsulated by an icosahedral protein-like structure and the RNA translates a single open reading frame flanked by two structured untranslated regions. Inside the host, the RNA genome is processed and cleaved by the host and viral proteases into three structural proteins [the capsid (C), pre-membrane (prM) and envelope (E)], as well as seven non-structural proteins (NS1, NS2A, NS2B, NS3, NS4A, NS4B, and NS5). ${ }^{15-17}$ The NS proteins are responsible for viral replication and assembly of the genome, as well as for hijacking the host cell's biochemical machinery for use by the virus. ${ }^{17}$ The E protein envelops the virus, which binds with the host membrane and facilitates fusion of the viral membrane
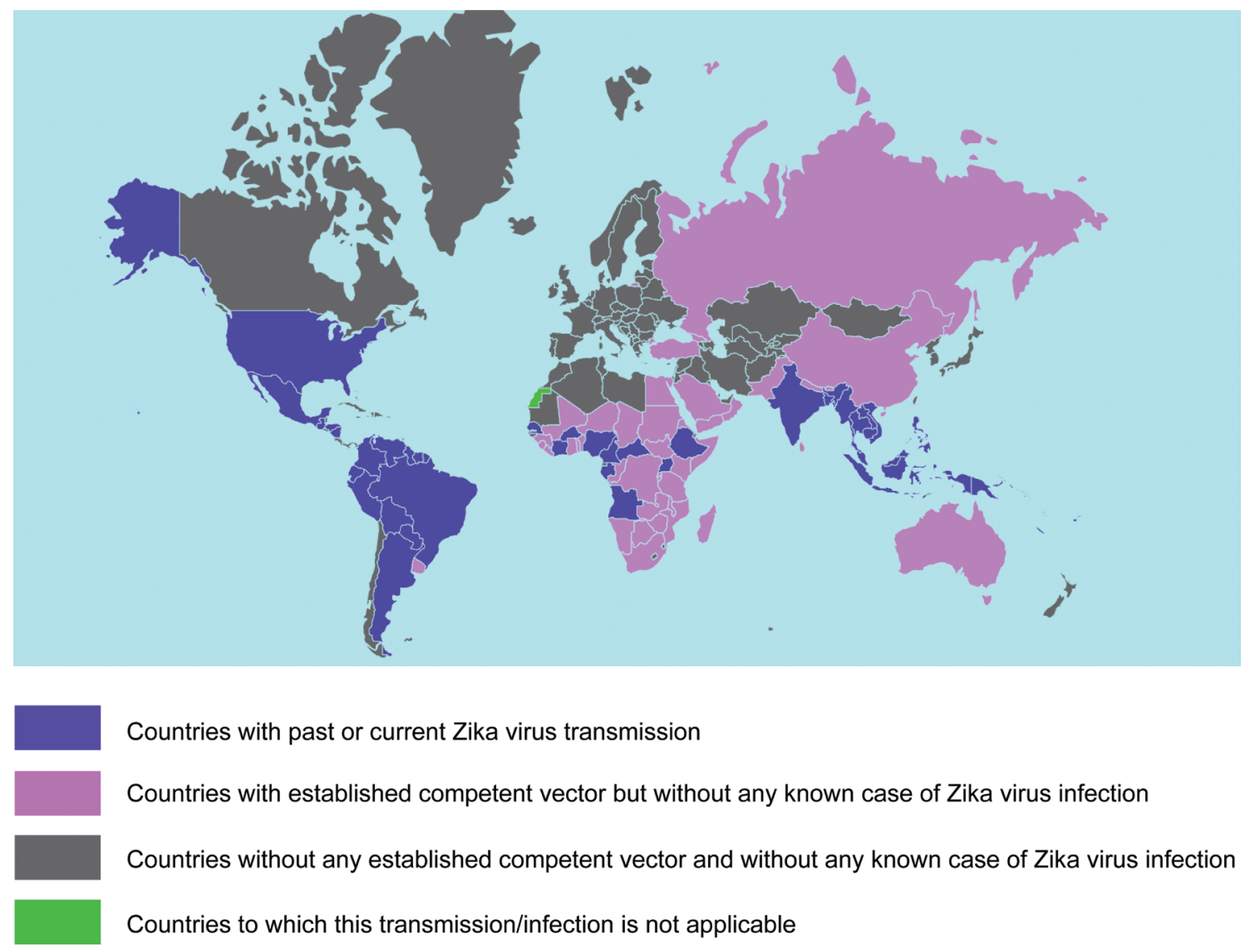

Countries with past or current Zika virus transmission

Countries with established competent vector but without any known case of Zika virus infection

Countries without any established competent vector and without any known case of Zika virus infection

Countries to which this transmission/infection is not applicable

Fig. 1. Geographical distribution of Zika virus spread. The map is drawn using data from the website: https://www.who.int/health-topics/zika-virusdisease\#tab=tab_1. 
with the host membrane to release the genomic RNA into the host cell cytoplasm. The E protein consists of three distinct domains that are bridged by the flexible fusion loops and are anchored with the viral membrane by a helical stem and two antiparallel transmembrane domains. ${ }^{17,18}$ It has been found in most Zika strains that the E protein is defined by a single N-linked glycan site at E154, which is located in domain 1 and was previously absent in some pre-epidemic strains from Africa. ${ }^{17}$ Zika virus is most closely related to another African Flavivirus, the Spondweni virus, where it exhibits approximately $68 \%$ homology in the amino acid composition of the E protein. Zika also exhibits about 50\% sequence similarity with Dengue virus strains, most notably Dengue type 2 virus, than all the other Flaviviruses. ${ }^{19,20}$ Previous studies have shown that Zika virus, along with other human pathogenic members of the Flavivirus, share four conserved surface-exposed regions of the E proteins. ${ }^{20}$ Although conserved regions can be targeted by vaccines or antibodies, there are many hurdles to overcome, such as whether human trials face any antibody-dependent enhancement effects similar to the Dengue infection. This also raises the prospect of adverse immune reactions in individuals exposed sequentially to Zika and Dengue viruses. ${ }^{21}$ Genetic analysis shows two distinct lineages of Zika virus with differential pathogenicity: African and non-African or Asian (which differ approximately from each other by $10 \%$ at the nucleotide level of the genome). A study by Faria et al. ${ }^{22}$ revealed that the American strains originated from the Asian lineage. Zika strains in the African lineage are more virulent compared to the Asian strains since they are more ancient in origin, have had time for many mutations and have induced stronger inflammatory responses in cytokines such as IL-6 or tumor necrosis factor (TNF). ${ }^{22,23}$ However, the pregnancy and neurological effects of Zika virus infection observed in Brazil and the Americas have not been noted in the African human lineage. ${ }^{12}$

The prM protein is a small glycoprotein that plays a significant role in the assembly of mature virions. This is done through the cleavage of prM into the membrane (M) protein upon exposure to the mildly acidic environment in the trans-Golgi network during the process of secretion by the host furin-like protease, and allows for the rearrangement of E proteins into homodimers and facilitates virion maturation. ${ }^{24,25}$ Another recent study revealed that the first 40 amino acids of the prM domain are influential regarding the interactions within trimeric spikes in the immature virus particle, and affects the dynamics of conformational changes that are important for viral packaging. ${ }^{25}$ The densities of the $\mathrm{C}$ protein can also differentiate between the immature and the mature virion and play an important role in the virus assembly process. ${ }^{26}$ Thus, understanding the role of these structural proteins for viral pathogenicity becomes significant in Zika vaccine development for the prevention, control, and therapeutic strategies of the virus.

To understand the role of the E and prM proteins associated with receptor binding during Zika virus infection, several structural studies have been employed at different resolutions. Sirohi et al. ${ }^{27}$ determined the structure of mature Zika virus at room temperature with a resolution of $3.8 \AA$ and Kostyuchenko et al..$^{28}$ did the same at $3.7 \AA$ at $40{ }^{\circ} \mathrm{C}$. Similarly, Prasad et al..$^{25}$ determined the structure of immature Zika virus at a resolution of $9.1 \AA$. According to the latest report by Sevvana et al., ${ }^{29}$ the refined structure of the mature Zika virus was determined at a resolution of $3.1 \AA$ by cryo-electron microscopy and was found to exhibit a large structural difference at the glycosylation loop associated with receptor binding. The authors of this work claimed that the results of the structural analysis would facilitate the process of vaccine design against Zika virus.

Previously, based on the microscopic structure, it was assumed that Zika virus exhibits icosahedral-like symmetry, similar to other flaviviruses. However, according to currently available studies these icosahedral viruses are not perfectly symmetrical, and rather have imperfect icosahedral symmetry, ${ }^{30}$ which indicates that there is a varied interaction between the core and glycoproteins. These deviations from icosahedral symmetry are thought to promote viral assembly and budding.

\section{Mutations of Zika virus}

Like other arboviruses, Zika virus has a considerable mutation rate due to the lack of error-checking and mismatch-repair mechanisms in its viral polymerases. ${ }^{31}$ Among the various mutations of Zika virus, some of enhanced virus fitness can lead to adaptive evolution and the emergence of outbreaks.

Shan et al..$^{32}$ showed that there was a single mutation in the viral envelope gene (E-V473M) of Zika virus which might be the underlying cause for the enhancement in its virulence and the high rate of maternal-to-foetal transmission during pregnancy seen since 2013. Liu et al. ${ }^{33}$ also showed that the NS1 (A188V) mutation is responsible for an enhancement in the virulence of Zika virus and is the underlying cause for the most recent outbreak in the Americas. Furthermore, it has been shown there that these newly evolved epidemic strains have higher NS1 antigenemia than previously isolated FSS13025 strains (isolated in Cambodia in 2010) in mosquitoes due to an alanine-to-valine amino acid substitution at residue 188 in NS1. The virulence of Zika virus can also be enriched by this amino acid substitution in the Zika FSS13025 strain in mosquitoes. ${ }^{33}$ Wang et al. ${ }^{34}$ also suggested that one pathogenic mutation at T233A, located at the dimer interface, in NS1 of Zika virus is responsible for neonatal microcephaly in South America. ${ }^{34}$ In addition, Yuan et al. ${ }^{35}$ revealed the presence of the S139N mutation in the precursor membrane protein of Zika virus, which first appeared in 2013 in French Polynesia, before the transmission of the virus to Brazil in 2015. These authors reported that due to this mutation, the virus was more infectious with enhanced virulence towards neural cell damage or death.

\section{Symptoms of Zika virus infection}

The majority of infected persons with Zika virus are asymptotic. In some cases, mild fever, rash, conjunctivitis, muscle and joint pain, malaise, and headaches are observed, and usually last for 2-7 days. However, Zika virus infection during pregnancy can often lead to microcephaly i.e., undeveloped, smaller size brain of the newborn baby. ${ }^{36}$ Infection with Zika virus is also associated with other complications during pregnancy, including premature birth and miscarriage. ${ }^{37} \mathrm{Zika}$ virus infections are often associated with congenital Zika syndrome which includes microcephaly, congenital malformation, foetal death, ${ }^{38-44}$ and Guillain-Barré syndrome which often manifests as muscle weakness and paralysis. ${ }^{45-48}$

\section{Transmission of Zika virus}

Zika virus is primarily transmitted by the bite of Aedes mosquitoes, which include the Aedes africanus, Aedes aegypti, Aedes hensilli, and Aedes albopictus species. ${ }^{49}$ There are other non-vector borne transmission modes which include sexual transmission, ${ }^{50}$ transmission from mother to child via placenta ${ }^{51}$ or through breast milk. ${ }^{52}$ Zika is also detected in and may be transmitted through semen, vaginal fluids, saliva and urine ${ }^{53}$ According to the reports of the CDC, National Centre for Emerging and Zoonotic Infec- 
tious Diseases, Division of Vector-Borne Diseases, dated July 24, $2019,{ }^{54}$ Zika virus is also transmitted through blood transfusion, laboratory and healthcare setting exposures and travelling. Advice for travellers are regularly available at the CDC website.

\section{Host immune responses against Zika infections}

For interaction between the virus and the host immune system, the interferon system is the mediator for innate immune responses and targets of viral counterattacks. On the other hand, the antibody and T-cell responses to viruses determine the outcome of adaptive immunity. Studies show that in cell culture and mice models, the primary immune response is generated in most cell types during Zika infections by generating type 1 interferons (IFNs). ${ }^{55-57}$ However, to facilitate viral infection, multiple yet distinct mechanisms inhibit the signal transduction pathways that induce IFN production and IFN-stimulated genes expression. ${ }^{58}$ In particular, Zika NS proteins have been found to target distinct signalling steps to inhibit type 1 interferon production. ${ }^{58}$ At present, interferon antagonism strategies mediated by early IFNs against Zika infection in vivo have yet to be explored even though they are the first line of defence against the pathogens. Answers to questions related to how Zika replicates and causes infection in animals lacking components of IFN signalling, like IFN $\alpha / \beta$ receptors ${ }^{57}$ and STAT2, may also provide novel insights into the mechanism of action of the interferon system. ${ }^{59}$

The E protein is the main target of neutralizing antibodies in Zika infections for humoral immunity provided by the host. ${ }^{60-62}$ Recently, E dimer epitope-specific antibodies derived from Dengue patients have shown cross-reaction with Zika virus and enhance its replication ${ }^{61,63}$ with implications for the antibody-dependent enhancement (ADE) of infection and disease. ADE plays an important role in Dengue pathogenesis in humans, and perhaps Zika too, ${ }^{21}$ although the molecular mechanisms of ADE are currently unknown. Further investigation of ADE mechanisms through clinical trials are required to design a potent vaccine.

Researchers are also investigating the role of T-cells in Zika immunity using animal models. Zika specific CD4+ and CD8+ $\mathrm{T}$ cell responses have been detected in virus-infected humans, non-human primates (cynomolgus macaques, rhesus macaques, and pigtail macaques) and mice. ${ }^{64-69}$ The immune response varies from population to population and between individuals due to the diversity at human leukocyte antigen (HLA) levels, and so epitopes of T-cell are very much specific for a particular ethnic group. One vaccine which induces adaptive immunity for a given population cannot be equally effective for all individuals since the immune protection will be different for each target population and will induce different levels of $\mathrm{B}$ cell and $\mathrm{T}$ cell responses.

\section{Vaccines development against Zika infection}

With the increasing frequency of viral epidemics and pandemics, designing vaccines to enhance the human immune response system has been the most promising weapon to combat viral infections. With the outbreak of Zika cases in Latin American countries in 2016 and complications associated with neurological and congenital diseases in newborns, the search for vaccines against infection intensified. Several vaccine trials are still ongoing in animal models to establish immunogenic protection against Zika, but no specific vaccine has yet been found effective. ${ }^{70}$ Among the greatest challenges for the rapid implementation of immunogenic, safe, and effective Zika vaccines is addressing potential side effects that may include Guillain-
Barré syndrome. This condition is a potential consequence of Zika virus infection and antibody enhancement, similar to cases of Dengue infections. ${ }^{71-74}$ The WHO Zika vaccine development roadmap provided two strategies for dealing with the infected population ${ }^{75}$ : One option involves mass vaccination of vulnerable populations, including pregnant women and women of child-bearing age during an ongoing epidemic, while the other involves the broad vaccination of the general population during inter-epidemic times. Presently, several vaccine candidates are in progress. These include DNA vaccines, purified inactivated viruses, live attenuated viruses, mRNA vaccines, and viral vectored vaccines (measles virus and adenovirus vectors). A few selected cases are as follows:

- The US National Institute of Allergy and Infectious Diseases (NIAID) is undertaking vaccine trials against the Zika virus infection. ${ }^{76}$ A DNA-based vaccine similar in platform to the flavivirus vaccine for West Nile virus infection, was created by scientists of NIAID's Vaccine Research Centre (VRC). A Phase 2 clinical trial was completed and showed potentially viable results. ${ }^{77}$ Later, the trial VRC 705 called for evaluating the safety and immunogenicity of the vaccine, as well as the appropriate dose to be administered.

- A purified inactivated form of Zika vaccine named ZPIV was developed by the Walter Reed Army Institute of Research (WRAIR). ${ }^{78,79}$ The concept of ZPIV is similar to the vaccines against the related Japanese Encephalitis and Dengue viruses. NIAID together with WRAIR came up with satisfactory results from multiple Phase 1 trials at the Beth Israel Deaconess Medical Centre and at other hospitals, which give hopes for future progress. ${ }^{80,81}$ Recently, using the same clinical batch of the first generation of ZPIV as a benchmark, Lecouturier et $a{ }^{79}$ reported that different doses of the optimized vaccine created by Sanofi Pasteur (ZPIV-SP) elicited sustained neutralizing antibodies, specific T-cells and memory B-cells, and provided absolute immunity against a Zika infection.

- An investigational live attenuated Zika vaccine known as rZIKV/D4 $30-713$ was developed by the researchers in the NIAID's Laboratory of Viral Diseases. This vaccine is a chimeric viral vaccine made of several genes from different viruses, mostly from Dengue serotypes using genetic engineering. Phase 1 clinical trials were initiated in August 2018 and are currently undergoing Phase 3 trials in Brazil. This vaccine is expected to be effective against both Zika and all four Dengue serotypes. ${ }^{76}$

- NIAID's VRC is working on potential mRNA vaccines in collaboration with GlaxoSmithKline, the University of Pennsylvania and Moderna/Valera to evaluate various mRNA vaccine technologies to identify immunogenic and scalable candidates. These vaccines are undergoing concurrent phase 1 and 2 clinical trials. ${ }^{82,83}$

- The investigational vaccine, called AGS-v was made by the London-based pharmaceutical company SEEK, which has since formed a joint venture with hVIVO in London to carry out clinical trials at the NIH Clinical Centre in Bethesda, Maryland, USA. This vaccine is a synthetic vaccine made from proteins of mosquito salivary glands, rather than viral proteins, that can prevent infection when a person is bitten by a diseasecarrying mosquito. ${ }^{76}$

- Several viral vector-based vaccines are also undergoing clinical trials and believed to be safe and non-pathogenic in humans. Phase 1 trials using a measles vector was performed in April $2018,{ }^{84}$ and similarly, a Phase 1 trial with an adenovirusbased vector for immunogenic Zika virus proteins was completed in 2019. ${ }^{85}$ Adenoviruses have been used effectively against HIV $^{86}$ and are currently being used as a platform for coronavirus disease 2019 (COVID-19), the illness caused by 
Table 2. The promising Zika vaccine candidates

\begin{tabular}{|c|c|c|}
\hline Developer & Status & Type of vaccine \\
\hline National Institute of Allergy and Infectious Diseases & In phase 2 clinical trials & DNA vaccine \\
\hline Walter Reed Army Institute of Research & In phase 1 clinical trials & Whole, purified, inactivated virus \\
\hline NIAID's Laboratory of Viral Diseases & In phase 3 clinical trials & $\begin{array}{l}\text { Live attenuated Zika vaccine (a chimeric viral vaccine } \\
\text { made from several genes from different viruses, mostly } \\
\text { from Dengue serotypes using genetic engineering). }\end{array}$ \\
\hline $\begin{array}{l}\text { NAID's Vaccine Research Centre in collaboration } \\
\text { with GlaxoSmithKline (GSK), University of } \\
\text { Pennsylvania and Moderna/Valera }\end{array}$ & $\begin{array}{l}\text { Concurrent phase } 1 \\
\text { and } 2 \text { clinical trials }\end{array}$ & mRNA vaccine \\
\hline $\begin{array}{l}\text { SEEK (London-based pharmaceutical company) } \\
\text { with hVIVO in London and NIH Clinical Centre in } \\
\text { Bethesda, Maryland. }\end{array}$ & Preclinical phase & $\begin{array}{l}\text { Synthetic vaccine (made from proteins } \\
\text { of mosquito salivary glands) }\end{array}$ \\
\hline Oxford university & $\begin{array}{l}\text { In phase } 1 \\
\text { clinical phase }\end{array}$ & Live adenovirus recombinant \\
\hline Themis Bioscience & $\begin{array}{l}\text { In phase } 1 \\
\text { clinical phase }\end{array}$ & Live measles recombinant \\
\hline University of Adelaide & Preclinical phase & T-cell based vaccine \\
\hline
\end{tabular}

the novel SARS-CoV-2 virus, treatments by scientists of Oxford University. ${ }^{87}$ Researchers from the University of Adelaide have also made significant advances in developing a novel Tcell based vaccine against a systemic Zika infection. This vaccine offers an advantage over other vaccines by eliminating the ongoing concerns in the field about the enhancement of infection following exposure to the Dengue virus. This work was funded by the National Foundation for Medical Research and Innovation and The Hospital Research Foundation, and is almost ready to go under clinical trials. ${ }^{88}$ To summarize, the promising Zika vaccine candidates are shown in the Table 2.

\section{Future perspective of Zika vaccine}

The development of a traditional vaccine is time-consuming and expensive. The emergence of new epidemics and pandemics with high degrees of severity demands the quick development of vaccines. To fulfil this demand, new paradigms in vaccine formulation have been developed. Peptide vaccine design is one such new approach which discards the "one-size-fits-all" concept and introduces the possibilities of population-orientated, community-specific and individual vaccine design. ${ }^{89,90}$

Due to the Zika virus epidemic of 2015-16, there have been several studies using immunoinformatic approaches to design peptide vaccines. ${ }^{91,92}$ Employing immunoinformatic and molecular dynamic simulations, Mirza et al. ${ }^{93}$ predicted antigenic epitopes of Zika viral proteins. Similarly, using an in-silico approach, Dar et $a l .{ }^{94}$ predicted promiscuous T-cell epitopes in the Zika polyprotein.

Our group has been working on peptide vaccine design by targeting conserved and surface-exposed regions of the virus. Our previous study suggested four peptide regions of the envelope protein E of Zika virus which are suitable for peptide vaccine development against this deadly virus. ${ }^{95}$ Some approximations used in the development have recently been replaced by more robust mathematical approaches - e.g. the 2D Polygon Representation model ${ }^{96,97}$ - to identify the most highly conserved and surface-accessible peptide regions. A detailed flow chart for searching for suitable peptide regions of Zika virus using this model is shown in Figure 2.
Using this new model, we have already reported various peptide regions suitable for vaccine design for SARS-CoV-2, ${ }^{96}$ and Ebola virus. $^{97}$

Applying this new model, five peptide regions of the E protein of Zika virus have been identified as probable vaccine candidates and have been suggested for wet laboratory experiments for the Zika virus vaccine. The list of identified peptide regions is shown in Table 3 (amino acid numbers based on protein sequence having Accession ID AHL43501.1). ${ }^{98}$

\section{The technological imperative}

The above discussions describe the considerable changes and progress in the Zika virus to date. Currently, with tremendous advances in immunoinformatics, genomics, information technology and developments in analytic and computational hardware, it is paramount to use the vast variety of available technological tools and techniques to mitigate and combat emerging diseases that may reach epidemic and pandemic levels. Basak et al. ${ }^{99}$ proposed a four-pronged approach to monitoring the epidemiology and characterization of suspected pathogens. This approach involved the consideration of fast computational methods to determine the novelty and the severity of the emerging pathogens, rapid assessment, and the development of vaccines. Such development spans across the creation of peptide vaccines and the computer-assisted design of therapeutics, to the development of new or repurposed drugs to help control the impact of the disease. Such applications in a fast-developing pandemic like the SARS-CoV-2 could conceivably help mitigate its effects, ${ }^{100}$ but these methods are still in a stage of infancy.

In another technological approach, Nandy et al. ${ }^{101,102}$ proposed setting up peptide vaccine labs and production centres at selected locations around the globe. While we have covered in many reviews the different approaches to designing peptide vaccines against pandemic viruses like Zika and COVID-19, several issues need to be resolved in the wet-lab environment before such vaccines can be safely and successfully marketed. With these issues taken care of and peptide vaccines accepted in the regulatory framework, one can conceive a situation where an emergent 


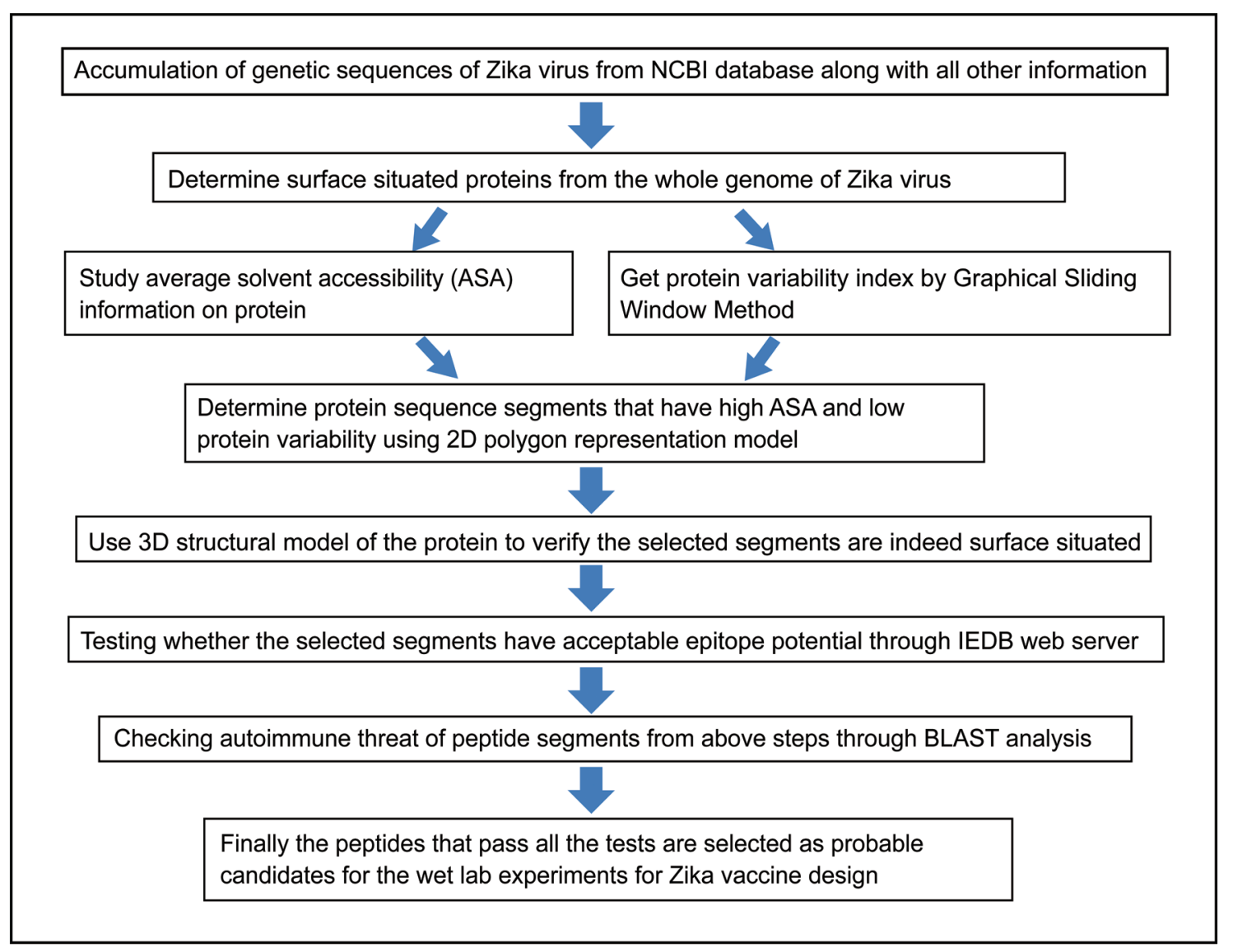

Fig. 2. Flow chart describing the search for suitable peptide regions of Zika virus.

epidemic virus is detected early, analysed in selected labs and the peptide targets identified for vaccine production. These targets can then to be electronically sent to the regional labs where they can be modified to better suit local communities through their HLA alleles and then mass produced to optimally mitigate the epidemic/ pandemic crises until more mature and well-tested vaccines are realised. This technology-based approach from start to finish could conceivably deliver a working product in a matter of months rather than years as more mature methodologies would require.

\section{Future direction}

To combat the epidemic/pandemic situations due to virus infection, the optimal option is the development of vaccines. After the latest outbreak of $\mathrm{Zika}$ virus and the emergence of various severe side effects, researchers all over the globe have focused on the development of safe and efficacious vaccines. Though there is not yet an accepted candidate for a Zika virus vaccine, there are many candidates currently under development that are in different stages of human clinical trials. The current race to develop viable vaccines against the SARS-CoV-2 virus follows this well-trodden path, although it seems that given the worldwide effort, results may be more forthcoming for this virus compared to Zika virus. Although Zika virus infection has already reduced significantly, the quest for suitable vaccines continues. According to various reports from WHO and CDC, though low numbers of new Zika virus infections are currently being reported, the virus is still circulating, especially in South and Southeast Asia. Therefore, the potential for new outbreaks exists and highlights the need to expedite vaccine development to guard against such eventualities.

To date, Zika virus vaccine development has followed tradi-

Table 3. List of identified peptide regions suitable for vaccine design against Zika virus

\begin{tabular}{ll}
\hline Amino acid range of identified regions & Amino acid sequence of identified regions \\
\hline $90-112$ & DIPLPWHAGADTGTPHWNNKEAL \\
$210-230$ & KVPAQMAVDMQTLTPVGRLIT \\
$38-56$ & EVTPNSPRAEATLGGFGSL \\
$230-250$ & TANPVITESTENSKMMLELDP \\
$13-25$ & VHGSQHSGMIVND \\
\hline
\end{tabular}


tional vaccine design protocols. However, with the reduction in virulence, the virus may be inactive in its current genetic form by the time such vaccines would be available on the market. Similar to other viruses, Zika virus can mutate frequently and create new forms of the virus. In these cases, traditional vaccines designed against current strains of the Zika virus may lose their relevance and be ineffective against mutated strains. In this context, peptide vaccines that are designed based on conserved (less mutable) and surface exposed regions (more binding ability to the receptor) of the virus may be a promising vaccine design protocol for the future. In this sense, more emphasis may be given to computational peptide vaccine design and experimental validation of the resultant peptide library for sustainable, community-specific peptide vaccine against Zika virus.

\section{Conclusions}

With the help of modern bioinformatics approaches, in association with biotechnology and computer assisted peptide and protein design technologies, it is necessary to have a readily available protocol for vaccine design to combat a virus so that quick action can be taken to mitigate the crisis. This framework would not only suggest vaccine candidates for Zika virus, but also provide a generalized protocol with a concrete mathematical foundation to help automate the process of identifying the best peptide vaccine candidates. Thus, in the future, such a framework has the potential to provide a rapid solution to vaccine design for any upcoming deadly virus.

\section{Acknowledgments}

None.

\section{Funding}

There were no funds or grants for the preparation of this review and manuscript.

\section{Conflict of interest}

The authors declare no conflict of interest.

\section{Author contributions}

AN organized and oversaw the study design, SD and SB reviewed the literature and interpreted the data, SM composed the manuscript assisted by SD. SCB provided overall guidance and critical review of the manuscript.

\section{References}

[1] PLISA Health Information Platform for the Americas. Cases of Zika Virus Disease. Available from: https://www.paho.org/data/index.php/ en/?option=com_content\&view; =article\&id;=524:zika-weekly-en\& Itemid;=352. Accessed September 15, 2020.

[2] Dick GW, Kitchen SF, Haddow AJ. Zika virus. I. Isolations and serological specificity. Trans R Soc Trop Med Hyg 1952;46(5):509-520. doi:10.1016/0035-9203(52)90042-4.
[3] Kindhauser MK, Allen T, Frank V, Santhana RS, Dye C. Zika: the origin and spread of a mosquito-borne virus. Bull world Health Organ 2016;94(9):675-686C. doi:10.2471/BLT.16.171082.

[4] WHO. Situation Report on Zika Virus, 10 March 2017. Available from: http://apps.who.int/iris/bitstream/10665/254714/1/zikasitrep10Mar17-eng.pdf?ua=1. Accessed September 15, 2020.

[5] Cao-Lormeau VM, Roche C, Teissier A, Robin E, Berry AL, Mallet HP, et al. Zika virus, French polynesia, South pacific, 2013. Emerg Infect Dis 2014;20(6):1085-1086. doi:10.3201/eid2006.140138.

[6] Musso D, Nilles EJ, Cao-Lormeau VM. Rapid spread of emerging Zika virus in the Pacific area. Clin Microbiol Infect 2014;20(10):0595O596. doi:10.1111/1469-0691.12707.

[7] Zanluca C, Melo VC, Mosimann AL, Santos GI, Santos CN, Luz K. First report of autochthonous transmission of Zika virus in Brazil. Mem Inst Oswaldo Cruz 2015;110(4):569-572. doi:10.1590/007402760150192.

[8] Grubaugh ND, Faria NR, Andersen KG, Pybus OG. Genomic Insights into Zika Virus Emergence and Spread. Cell 2018;172(6):1160-1162. doi:10.1016/j.cell.2018.02.027.

[9] Wongsurawat T, Athipanyasilp N, Jenjaroenpun P, Jun SR, Kaewnapan B, Wassenaar TM, et al. Case of microcephaly after congenital infection with Asian lineage Zika virus, Thailand. Emerg Infect Dis 2018;24(9):1758-1761. doi:10.3201/eid2409.180416.

[10] Lan PT, Quang LC, Huong VTQ, Thuong NV, Hung PC, Huong TTLN, et al. Fetal Zika Virus Infection in Vietnam. PLoS Curr 2017;9:ecurrents. outbreaks.1c8f631e0ef8cd7777d639eba48647fa. doi:10.1371/currents.outbreaks.1c8f631e0ef8cd7777d639eba48647fa.

[11] Moi ML, Nguyen TTT, Nguyen CT, Vu TBH, Tun MMN, Pham TD, et al. Zika virus infection and microcephaly in Vietnam. Lancet Infect Dis 2017;17(8):805-806. doi:10.1016/S1473-3099(17)30412-7.

[12] WHO. Zika epidemiology update. Available from: https://www.who. int/emergencies/diseases/zika/zika-epidemiology-update-july-2019. pdf?ua=1. Accessed September 15, 2020.

[13] Centers for Disease Control and Prevention. 2020 Case Counts in the US. Available from: https://www.cdc.gov/zika/reporting/2020-casecounts.html. Accessed September 15, 2020.

[14] Vasilakis N, Weaver SC. Flavivirus transmission focusing on Zika. Curr Opin Virol 2017;22:30-35. doi:10.1016/j.coviro.2016.11.007.

[15] Nitatpattana N, Chaiyo K, Rajakam S, Poolam K, Chansiprasert K, Pesirikan N, et al. Complete Genome Sequence of a Zika Virus Strain Isolated from the Serum of an Infected Patient in Thailand in 2006. Genome Announc 2018;6(10):e00121-18. doi:10.1128/genomeA.00121-18.

[16] Shrinet J, Agrawal A, Bhatnagar RK, Sujatha Sunil S. Analysis of the genetic divergence in Asian strains of ZIKA virus with reference to 2015-2016 outbreaks. Bull World Health Organ 2016. doi:10.2471/ BLT.16.176065.

[17] Pierson TC, Diamond MS. The emergence of Zika virus and its new clinical syndromes. Nature 2018;560(7720):573-581. doi:10.1038/ s41586-018-0446-y.

[18] Zhang X, Jia R, Shen H, Wang M, Yin Z, Cheng A. Structures and Functions of the Envelope Glycoprotein in Flavivirus Infections. Viruses 2017;9(11):338. doi:10.3390/v9110338.

[19] Chang HH, Huber RG, Bond PJ, Grad YH, Camerini D, Maurer-Stroh $\mathrm{S}$, et al. Systematic analysis of protein identity between Zika virus and other arthropod-borne viruses. Bull World Health Organ 2017;95(7):517-525I. doi:10.2471/BLT.16.182105.

[20] Dey S, Das S, Nandy A. Characterization of Zika and Other Human Infecting Flavivirus Envelope Proteins and Determination of Common Conserved Epitope Regions. EC Microbiology 2017;8(1):29-46.

[21] Martín-Acebes MA, Saiz JC, Jiménez de Oya N. Antibody-Dependent Enhancement and Zika: Real Threat or Phantom Menace? Front Cell Infect Microbiol 2018;8:44. doi:10.3389/fcimb.2018.00044.

[22] Faria NR, Quick J, Claro IM, Thézé J, de Jesus JG, Giovanetti M, et al. Establishment and cryptic transmission of Zika virus in Brazil and the Americas. Nature 2017;546(7658):406-410. doi:10.1038/nature 22401.

[23] Nandy A, Dey S, Basak SC, Bielinska-Waz D, Waz P. Characterizing the Zika Virus Genome - A Bioinformatics Study. Curr Comput Aided Drug Des 2016;12(2):87-97. doi:10.2174/1573409912666160401115812.

[24] Nambala P, Su WC. Role of Zika Virus prM Protein in Viral Pathogenicity and Use in Vaccine Development. Front Microbiol 2018;9:1797. 
doi:10.3389/fmicb.2018.01797.

[25] Prasad VM, Miller AS, Klose T, Sirohi D, Buda G, Jiang W, et al. Structure of the immature Zika virus at $9 \AA$ A resolution. Nat Struct Mol Biol 2017;24(2):184-186. doi:10.1038/nsmb.3352.

[26] Tan TY, Fibriansah G, Kostyuchenko VA, Ng TS, Lim XX, Zhang S, et al. Capsid protein structure in Zika virus reveals the flavivirus assembly process. Nat Commun 2020;11(1):895. doi:10.1038/s41467-02014647-9.

[27] Sirohi D, Chen Z, Sun L, Klose T, Pierson TC, Rossmann MG, et al. The $3.8 \AA$ resolution cryo-EM structure of Zika virus. Science 2016;352(6284):467-470. doi:10.1126/science.aaf5316.

[28] Kostyuchenko VA, Lim EX, Zhang S, Fibriansah G, Ng TS, Ooi JS, et al. Structure of the thermally stable Zika virus. Nature 2016;533(7603):425-428. doi:10.1038/nature17994.

[29] Sevvana M, Long F, Miller AS, Klose T, Buda G, Sun L, et al. Refinement and Analysis of the Mature Zika Virus Cryo-EM Structure at 3.1 Å Resolution. Structure 2018;26(9):1169-1177.e3. doi:10.1016/j. str.2018.05.006.

[30] Therkelsen MD, Klose T, Vago F, Jiang W, Rossmann MG, Kuhn RJ. Flaviviruses have imperfect icosahedral symmetry. PNAS 2018;115(45):11608-11612. doi:10.1073/pnas.1809304115.

[31] Logan IS. ZIKA-How fast does this virus mutate? Dongwuxue Yanjiu 2016;37(2):110-115. doi:10.13918/j.issn.2095-8137.2016.2.110.

[32] Shan C, Xia H, Haller SL, Azar SR, Liu Y, Liu J, et al. A Zika virus envelope mutation preceding the 2015 epidemic enhances virulence and fitness for transmission. PNAS 2020;117(33):20190-20197. doi:10.1073/pnas.2005722117.

[33] Liu Y, Liu J, Du S, Shan C, Nie K, Zhang R, et al. Evolutionary enhancement of Zika virus infectivity in Aedes aegypti mosquitoes. Nature 2017;545(7655):482-486. doi:10.1038/nature22365.

[34] Wang D, Chen C, Liu S, Zhou H, Yang K, Zhao Q, et al. A Mutation Identified in Neonatal Microcephaly Destabilizes Zika Virus NS1 Assembly in Vitro. Sci Rep 2017;7:42580. doi:10.1038/srep42580.

[35] Yuan L, Huang XY, Liu ZY, Zhang F, Zhu XL, Yu JY, et al. A single mutation in the prM protein of Zika virus contributes to fetal microcephaly. Science 2017;358(6365):933-936. doi:10.1126/science.aam7120.

[36] Wen Z, Song H, Ming GL. How does Zika virus cause microcephaly? Genes Dev 2017;31(9):849-861. doi:10.1101/gad.298216.117.

[37] Dudley DM, Van Rompay KK, Coffey LL, Ardeshir A, Keesler RI, BlissMoreau $\mathrm{E}$, et al. Miscarriage and stillbirth following maternal Zika virus infection in nonhuman primates. Nat Med 2018;24(8):11041107. doi:10.1038/s41591-018-0088-5.

[38] Mlakar J, Korva M, Tul N, Popović M, Poljšak-Prijatelj M, Mraz J, et al. Zika Virus Associated with Microcephaly. N Engl J Med 2016; 374(10):951-958. doi:10.1056/NEJMoa1600651.

[39] Brasil P, Pereira JP Jr, Moreira ME, Ribeiro Nogueira RM, Damasceno $\mathrm{L}$, Wakimoto $\mathrm{M}$, et al. Zika Virus Infection in Pregnant Women in Rio de Janeiro. N Engl J Med 2016;375(24):2321-2334. doi:10.1056/NEJMoa1602412.

[40] Kleber de Oliveira W, Cortez-Escalante J, De Oliveira WT, do Carmo GM, Henriques CM, Coelho GE, et al. Increase in Reported Prevalence of Microcephaly in Infants Born to Women Living in Areas with Confirmed Zika Virus Transmission During the First Trimester of Pregnancy - Brazil, 2015. MMWR Morb Mortal Wkly Rep 2016;65(9):242247. doi:10.15585/mmwr.mm6509e2.

[41] Heymann DL, Hodgson A, Sall AA, Freedman DO, Staples JE, Althabe F, et al. Zika virus and microcephaly: why is this situation a PHEIC? Lancet 2016;387(10020):719-721. doi:10.1016/S0140-6736(16)00320-2.

[42] Hoen B, Schaub B, Funk AL, Ardillon V, Boullard M, Cabié A, et al. Pregnancy Outcomes after ZIKV Infection in French Territories in the Americas. N Engl J Med 2018;378(11):985-994. doi:10.1056/NEJMoa1709481.

[43] Panchaud A, Stojanov M, Ammerdorffer A, Vouga M, Baud D. Emerging Role of Zika Virus in Adverse Fetal and Neonatal Outcomes. Clin Microbiol Rev 2016;29(3):659-694. doi:10.1128/CMR.00014-16.

[44] Coyne CB, Lazear HM. Zika virus - reigniting the TORCH. Nat Rev Microbiol 2016;14(11):707-715. doi:10.1038/nrmicro.2016.125.

[45] Besnard M, Lastere S, Teissier A, Cao-Lormeau V, Musso D. Evidence of perinatal transmission of Zika virus, French Polynesia, December 2013 and February 2014. Euro Surveill 2014;19(13):20751. doi:10.2807/1560-7917.ES2014.19.13.20751.
[46] Méndez N, Oviedo-Pastrana M, Mattar S, Caicedo-Castro I, Arrieta G. Zika virus disease, microcephaly and Guillain-Barré syndrome in Colombia: epidemiological situation during 21 months of the Zika virus outbreak, 2015-2017. Arch Public Health 2017;75:65. doi:10.1186/ s13690-017-0233-5.

[47] Barbi L, Coelho AVC, Alencar LCA, Crovella S. Prevalence of Guillain-Barré syndrome among Zika virus infected cases: a systematic review and meta-analysis. Braz J Infect Dis 2018;22(2):137-141. doi:10.1016/j.bjid.2018.02.005.

[48] Styczynski AR, Malta JMAS, Krow-Lucal ER, Percio J, Nóbrega ME, Vargas $A$, et al. Increased rates of Guillain-Barré syndrome associated with Zika virus outbreak in the Salvador metropolitan area, Brazil. PLoS Negl Trop Dis 2017;11(8):e0005869. doi:10.1371/journal. pntd.0005869.

[49] WHO.LaboratorytestingforZikavirusinfection.Availablefrom:https:// www.who.int/csr/resources/publications/zika/laboratory-testing/ en/. Accessed September 15, 2020.

[50] Sakkas H, Bozidis P, Giannakopoulos X, Sofikitis N, Papadopoulou C. An Update on Sexual Transmission of Zika Virus. Pathogens 2018;7(3):66. doi:10.3390/pathogens7030066.

[51] Mysorekar IU. Zika Virus Takes a Transplacental Route to Infect Fetuses: Insights from an Animal Model. Mo Med 2017;114(3):168-170.

[52] Cavalcanti MG, Cabral-Castro MJ, Gonçalves JLS, Santana LS, Pimenta ES, Peralta JM. Zika virus shedding in human milk during lactation: an unlikely source of infection? Int J Infect Dis 2017;57:70-72. doi:10.1016/j.ijid.2017.01.042.

[53] Plourde AR, Bloch EM. A Literature Review of Zika Virus. Emerg Infect Dis 2016;22(7):1185-1192. doi:10.3201/eid2207.151990.

[54] Centers for Disease Control and Prevention. Zika Transmission. Available from: https://www.cdc.gov/zika/prevention/transmissionmethods.html\#: :text=Zika\%20virus\%20is\%20transmitted\%20 to,spread\%20dengue\%20and\%20chikungunya\%20viruses. Accessed September 15, 2020.

[55] Hamel R, Dejarnac O, Wichit S, Ekchariyawat P, Neyret A, Luplertlop $\mathrm{N}$, et al. Biology of Zika Virus Infection in Human Skin Cells. J Virol 2015;89(17):8880-8896. doi:10.1128/JVI.00354-15.

[56] Kumar A, Hou S, Airo AM, Limonta D, Mancinelli V, Branton W, et al. Zika virus inhibits type-I interferon production and downstream signaling. EMBO Rep 2016;17(12):1766-1775. doi:10.15252/embr. 201642627.

[57] Lazear HM, Govero J, Smith AM, Platt DJ, Fernandez E, Miner JJ, et al. A Mouse Model of Zika Virus Pathogenesis. Cell Host Microbe 2016;19(5):720-730. doi:10.1016/j.chom.2016.03.010.

[58] Serman TM, Gack MU. Evasion of Innate and Intrinsic Antiviral Pathways by the Zika Virus. Viruses 2019;11(10):970. doi:10.3390/v111 00970.

[59] Tripathi S, Balasubramaniam VR, Brown JA, Mena I, Grant A, Bardina $\mathrm{SV}$, et al. A novel Zika virus mouse model reveals strain specific differences in virus pathogenesis and host inflammatory immune responses. PLoS Pathog 2017;13(3):e1006258. doi:10.1371/journal.ppat. 1006258.

[60] Sapparapu G, Fernandez E, Kose N, Bin Cao, Fox JM, Bombardi RG, et al. Neutralizing human antibodies prevent Zika virus replication and fetal disease in mice. Nature 2016;540(7633):443-447. doi:10.1038/ nature20564.

[61] Stettler K, Beltramello M, Espinosa DA, Graham V, Cassotta A, Bianchi $\mathrm{S}$, et al. Specificity, cross-reactivity, and function of antibodies elicited by Zika virus infection. Science 2016;353(6301):823-826. doi:10.1126/science.aaf8505.

[62] Wang Q, Yang H, Liu X, Dai L, Ma T, Qi J, et al. Molecular determinants of human neutralizing antibodies isolated from a patient infected with Zika virus. Sci Transl Med 2016;8(369):369ra179. doi:10.1126/ scitranslmed.aai8336.

[63] Langerak T, Mumtaz N, Tolk VI, van Gorp ECM, Martina BE, Rockx B, et al. The possible role of cross-reactive dengue virus antibodies in Zika virus pathogenesis. PLoS Pathog 2019;15(4):e1007640. doi:10.1371/ journal.ppat.1007640.

[64] EstesJD, Wong SW, BrenchleyJM. Nonhuman primate models of human viral infections. Nat Rev Immunol 2018;18(6):390-404. doi:10.1038/ s41577-018-0005-7.

[65] Badolato-Corrêa J, Sánchez-Arcila JC, Alves de Souza TM, Santos Bar- 
bosa L, Conrado Guerra Nunes P, da Rocha Queiroz Lima M, et al. Human $T$ cell responses to Dengue and Zika virus infection compared to Dengue/Zika coinfection. Immun Inflamm Dis 2018;6(2):194-206. doi:10.1002/iid3.203.

[66] Grifoni A, Pham J, Sidney J, O'Rourke PH, Paul S, Peters B, et al. Prior Dengue Virus Exposure Shapes T Cell Immunity to Zika Virus in Humans. J Virol 2017;91(24):e01469-17. doi:10.1128/JVI.01469-17.

[67] Dudley DM, Aliota MT, Mohr EL, Weiler AM, Lehrer-Brey G, Weisgrau $\mathrm{KL}$, et al. A rhesus macaque model of Asian-lineage Zika virus infection. Nat Commun 2016;7:12204. doi:10.1038/ncomms12204.

[68] Osuna CE, Lim SY, Deleage C, Griffin BD, Stein D, Schroeder LT, et al. Zika viral dynamics and shedding in rhesus and cynomolgus macaques. Nat Med 2016;22(12):1448-1455. doi:10.1038/nm.4206

[69] Pardy RD, Rajah MM, Condotta SA, Taylor NG, Sagan SM, Richer MJ. Analysis of the $T$ Cell Response to Zika Virus and Identification of a Novel CD8+ T Cell Epitope in Immunocompetent Mice. PLoS Pathog 2017;13(2):e1006184. doi:10.1371/journal.ppat.1006184.

[70] Pattnaik A, Sahoo BR, Pattnaik AK. Current Status of Zika Virus Vaccines: Successes and Challenges. Vaccines (Basel) 2020;8(2):266 doi:10.3390/vaccines8020266.

[71] Barouch DH, Thomas SJ, Michael NL. Prospects for a Zika Virus Vaccine. Immunity 2017;46(2):176-182. doi:10.1016/j.immuni.2017.02.005.

[72] Saiz JC, Martín-Acebes MA, Bueno-Marí R, Salomón OD, VillamilJiménez LC, Heukelbach J, et al. Zika Virus: What Have We Learnt Since the Start of the Recent Epidemic? Front Microbiol 2017;8:1554. doi:10.3389/fmicb.2017.01554.

[73] Priyamvada L, Hudson W, Ahmed R, Wrammert J. Humoral cross-reactivity between Zika and dengue viruses: implications for protection and pathology. Emerg Microbes Infect 2017;6(5):e33. doi:10.1038/ emi.2017.42.

[74] Ghaffar KA, Ng LFP, Renia L. Fast Tracks and Roadblocks for Zika Vaccines. Vaccines (Basel) 2018;6(4):77. doi:10.3390/vaccines6040077.

[75] WHO. Zika Virus Vaccine Product Development. Available from: https://www.who.int/immunization/research/development/zika/en. Accessed April 25, 2020.

[76] NIH: National Institute of Allergy and Infectious Diseases. Zika Virus Vaccines. Available from: https://www.niaid.nih.gov/diseases-conditions/zika-vaccines. Accessed September 7, 2020.

[77] NIH: National Institute of Allergy and Infectious Diseases. Phase 2 Zika Vaccine Trial Begins in U.S., Central and South America. Available from: https://www.nih.gov/news-events/news-releases/phase2-zika-vaccine-trial-begins-us-central-south-america. Accessed September 15, 2020.

[78] NIH: National Institute of Allergy and Infectious Diseases. Available from: https://www.nih.gov/news-events/news-releases/testinginvestigational-inactivated-zika-vaccine-humans-begins. Accessed September 15, 2020.

[79] Lecouturier V, Pavot V, Berry C, Donadieu A, de Montfort A, Boudet $F$, et al. An optimized purified inactivated Zika vaccine provides sustained immunogenicity and protection in cynomolgus macaques. NPJ Vaccines 2020;5:19. doi:10.1038/s41541-020-0167-8.

[80] Reuters. Trial results of Zika vaccine Sanofi dropped show promise. Available from: https://www.nst.com.my/lifestyle/heal/2017/12/310819/ trial-results-zika-vaccine-sanofi-dropped-show-promise. Accessed September 15, 2020.

[81] Modjarrad K, Lin L, George SL, Stephenson KE, Eckels KH, De La Barrera RA, et al. Preliminary aggregate safety and immunogenicity results from three trials of a purified inactivated Zika virus vaccine candidate: phase 1, randomised, double-blind, placebo-controlled clinical trials. Lancet 2018;391(10120):563-571. doi:10.1016/S01406736(17)33106-9.

[82] ClinicalTrials.gov. Safety, Tolerability, and Immunogenicity of mRNA 1325 in Healthy Adult Subjects. Available from: https://clinicaltrials. gov/ct2/show/NCT03014089. Accessed September 30, 2020.

[83] Fernandez E, Diamond MS. Vaccination strategies against Zika virus. Curr Opin Virol 2017;23:59-67. doi:10.1016/j.coviro.2017.03.006

[84] ClinicalTrials.gov. Zika-Vaccine Dose Finding Study Regarding Safety, Immunogenicity and Tolerability. Available from: https://clinicaltrials.gov/ct2/show/NCT02996890. Accessed September 15, 2020.

[85] ClinicalTrials.gov. A Study to Evaluate the Safety, Reactogenicity and Immunogenicity of Ad26.ZIKV.001 in Healthy Adult Volunteers. Avail- able from: https://clinicaltrials.gov/ct2/show/NCT03356561. Accessed September 15, 2020.

[86] Baden LR, Karita E, Mutua G, Bekker LG, Gray G, Page-Shipp L, et al. Assessment of the Safety and Immunogenicity of 2 Novel Vaccine Platforms for HIV-1 Prevention: A Randomized Trial. Ann Intern Med 2016;164(5):313-322. doi:10.7326/M15-0880.

[87] Zhu FC, Guan XH, Li YH, Huang JY, Jiang T, Hou LH, et al. Immunogenicity and safety of a recombinant adenovirus type-5-vectored COVID-19 vaccine in healthy adults aged 18 years or older: a randomised, double-blind, placebo-controlled, phase 2 trial. Lancet 2020;396(10249):479-488. doi:10.1016/S0140-6736(20)31605-6.

[88] Grubor-Bauk B, Wijesundara DK, Masavuli M, Abbink P, Peterson RL, Prow NA, et al. NS1 DNA vaccination protects against Zika infection through T cell-mediated immunity in immunocompetent mice. Sci Adv 2019;5(12):eaax2388. doi:10.1126/sciadv.aax2388.

[89] Poland GA, Kennedy RB, Ovsyannikova IG. Vaccinomics and personalized vaccinology: is science leading us toward a new path of directed vaccine development and discovery? PLoS Pathog 2011 7(12):e1002344. doi:10.1371/journal.ppat.1002344

[90] Poland GA, Whitaker JA, Poland CM, Ovsyannikova IG, Kennedy RB. Vaccinology in the third millennium: scientific and social challenges. Curr Opin Virol 2016;17:116-125. doi:10.1016/j.coviro.2016.03.003.

[91] Shawan MMAK, Mahmud HA, Hasan MM, Parvin A, Rahman MN Rahman SMB. In Silico Modeling and Immunoinformatics probing disclose the epitope based peptide vaccine against Zika virus envelope glycoprotein. Indian J Pharma Biol Res 2014;2:44-57. doi:10.30750/ ijpbr.2.4.10.

[92] Badawi MM, Osman MM, Alla AAEF, Ahmedani AM, Abdalla $\mathrm{MH}$ Gasemelseed MM, et al. Highly conserved epitopes of ZIKA envelope glycoprotein may act as a novel peptide vaccine with high coverage: Immunoinformatics approach. Am J Biomed Res 2016;4(3):46-60.

[93] Mirza MU, Rafique S, Ali A, Munir M, Ikram N, Manan A, et al. Towards peptide vaccines against Zika virus: Immunoinformatics combined with molecular dynamics simulations to predict antigenic epitopes of Zika viral proteins. Sci Rep 2016;6:37313. doi:10.1038/ srep37313.

[94] Dar H, Zaheer T, Rehman MT, Ali A, Javed A, Khan GA, et al. Prediction of promiscuous T-cell epitopes in the Zika virus polyprotein: An in silico approach. Asian Pac J Trop Med 2016;9(9):844-850. doi:10.1016/j.apjtm.2016.07.004.

[95] Dey S, Nandy A, Basak SC, Nandy P, Das S. A Bioinformatics approach to designing a Zika virus vaccine. Comput Biol Chem 2017;68:143152. doi:10.1016/j.compbiolchem.2017.03.002.

[96] Biswas S, Chatterjee S, Dey T, Dey S, Manna S, Nandy A, et al. In Silico Approach for Peptide Vaccine Design for CoVID 19. MOL2NET, International Conference Series on Multidisciplinary Sciences, 6th Edition; USINEWS-04: US-IN-EU Worldwide Science Workshop Series, UMN Duluth, USA, 2020. doi:10.3390/mol2net-06-06787.

[97] Biswas S, Dey T, Chatterjee S, Manna S, Nandy A, Das S, et al. A novel approach to Peptide Vaccine Design for Ebola virus. MOL2NET, International Conference on Multidisciplinary Sciences, 5th edition; USINEWS-03: US-IN-EU Worldwide Science Workshop Series, UMN Duluth, USA, 2019. doi:10.3390/mol2net-05-06712.

[98] National Library of Medicine (US), National Center for Biotechnology Information. polyprotein [Zika virus]. Available from: https://www. ncbi.nlm.nih.gov/nuccore/AHL43501.1. Accessed May 08, 2020.

[99] Basak SC, Bhattacharjee A, Nandy A. Zika Virus Surveillance, Vaccinology, and Anti-Zika Drug Discovery: Computer-Assisted Strategies to Combat the Menace. New York: Nova Science Publishers 2019.

[100] Basak SC, Majumdar S, Vracko M, Nandy A, Bhattacharjee A. A Generic Computer-Assisted Four-Pronged Approach for the Management of Emerging Global Pathogens: Some Comments on COVID-19. Curr Comput Aided Drug Des 2020;16(4):351-353. doi:10.2174/157 3409916999200316102548.

[101] Nandy A, Dey S, Roy P, Basak SC. Epidemics and Peptide Vaccine Response: A Brief Review. Curr Top Med Chem 2018;18(26):2202-2208. doi:10.2174/1568026618666181112144745.

[102] Nandy A, Basak SC. Towards personalized vaccines - Tailoring peptide vaccines to demographic groups and individuals. Med One 2019;4:e190026. doi:10.20900/mo.20190026 